City University of New York (CUNY) CUNY Academic Works

\title{
Analysis of the system response of a spray passive downdraft evaporative cooling system
}

Daeho Kang

CUNY New York City College of Technology

Richard K. Strand

University of Illinois at Urbana-Champaign

\section{How does access to this work benefit you? Let us know!}

More information about this work at: https://academicworks.cuny.edu/ny_pubs/373

Discover additional works at: https://academicworks.cuny.edu

This work is made publicly available by the City University of New York (CUNY).

Contact: AcademicWorks@cuny.edu 


\title{
Analysis of the system response of a spray passive downdraft evaporative cooling system
}

\author{
Daeho Kanga* and Richard K. Strand ${ }^{\mathrm{b}}$ \\ ${ }^{a}$ Department of Environmental Control Technology and Facilities Management, New York City College of \\ Technology, The City University of New York, 186 Jay Street, Brooklyn, NY, 11201, USA \\ b Illinois School of Architecture, University of Illinois at Urbana-Champaign, 611 Lorado Taft Drive, \\ Champaign, IL, 61820, USA \\ * Corresponding author \\ Email address: airguider@gmail.com; dkang@citytech.cuny.edu
}

Keywords: Evaporative cooling, Simulation, Spray, Cooling load, Thermal comfort, Airflow

\begin{abstract}
A spray Passive Downdraft Evaporative Cooling (PDEC) system achieves great savings for space cooling and improves indoor environmental quality by supplying a large amount of fresh outdoor air. As previous studies heavily focused on the energy saving capability of a spray PDEC system due to lack of methods for a detailed analysis, the influence of cool humid supply air from a spray PDEC system in a space in buildings has not been comprehensively studied. This study is intended to evaluate the competence of a spray PDEC system as a primary cooling system in typical spaces in a primary school building by developing a method using building energy simulation tool. It runs one-day simulations in a hot dry climate and a warm moderate climate in order to distinctly examine the benefits and the areas that should be advanced. It analyses how a spray PDEC system responds to the space cooling loads and spaces conditioned by the system thermally behave. The results of the simulations affirm that a spray PDEC system is capable of conditioning building spaces in the two climates, indicating some areas to be improved.
\end{abstract}

\section{Introduction}

A wind tower that consists of a wind catcher, a shaft, and bottom openings is the simplest form of evaporative cooling applications in the cooling of buildings and has been used for decades [1-4]. As wind towers achieved marginal cooling effects, direct evaporative cooling technology has been introduced to enhance the performance of wind towers [5-7]. Initial designs of a spray passive down-draft evaporative cooling (PDEC) system was introduced in the 1980s [1,8], and thereafter it has been used in the cooling of buildings for the following decades [6,7,9-12]. Early building applications for direct evaporative cooling systems were typically designed to achieve the highest wet bulb depression (WBD), which is the difference between dry and wet bulb temperature. As direct evaporative cooling applications significantly affect the indoor humidity level, many studies evaluated different approaches to mitigate inborn impediments of these systems [13-18].

Studies reported that the applications using PDEC technology achieved substantial energy savings for space cooling in buildings [6,19,20-22]. The results of post-occupancy surveys and field measurements showed that a spray PDEC system may maintain a satisfactory indoor thermal environment $[4,11,22,23]$. Ford et al. [6] compared buildings served by a spray PDEC system and a mechanical air-conditioning system. The outcomes of the post-occupancy evaluation in the study showed occupants' satisfaction in the building that a spray PDEC system conditioned was similar to the other while leading to greater variability of the responses in the seven-scale rating for 12 questions. On the other hand, a large amount of water consumption is one of the key problems as hot-dry climates, where a spray PDEC system performs best, are typically a lack of water resources. Another problem is that the cooling capacity of a spray PDEC system 
is inconsistent and insufficient to meet the variable space cooling loads, due to strong climatic dependency $[1,6,14,19,20]$.

To date, many studies followed to advance the cooling performance of spray PDEC systems and to understand the down-draft evaporative cooling process [2,5,6,9,17,19,24-26]. Ford et al. [27] investigated energy performance in Torrent Research Center (TRC) building in Ahmedabad, India. The study showed that a spray PDEC system conditioned the buildings well and achieved $10-14^{\circ} \mathrm{C}$ temperature drops. Bahadori et al. [5] designed new types of direct evaporative cooling systems and tested the new designs in the city of Yazd, Iran. They include a traditional wind tower, a PDEC with a pad, and a spray PDEC tower with fabric curtains. The results of the measurement showed that both evaporative cooling towers performed better. Omar Dhia Sadulah Al-Hassawi [28] experimented two types of evaporative cooling towers: a passive down-draft evaporative cooling tower (PDECT) and a passive hybrid down-draft cooling tower (PHDCT) that is the combination of a PDECT and an indirect down-draft evaporative cooling tower in Arizona, USA. The performance of the PHDCT was nearly identical under the two different climatic conditions while that of the PDECT decreased significantly under hot-humid conditions.

It is generally known that evaporative cooling is immediate and energy-efficient as it needs the supply of water with no mechanical components for the vapor-compression cooling cycle. Spray evaporative cooling has been typically used for a large open space as the cooling performance is strongly dependent on the climatic conditions. The system response to variable cooling loads is thus inherently a challenge since a spray PDEC system handles a large amount of airflow whose conditions consistently vary. Many parameters are also involved with the down-draft evaporative cooling process such as the WBD, air and water mass flow rates, water droplet sizes, and physical tower dimensions. No study has investigated how well a spray PDEC system can respond to the cooling loads in buildings to date as no reliable methods have been available. To remedy this gap, this study analyzes the ability of a spray PDEC system to meet the cooling loads and compares its capability with typical air-conditioning systems.

\section{Theory}

\subsection{Analytical models}

The authors of this study have been conducting a series of works to develop a reliable method for a comprehensive analysis of a spray PDEC system $[14,19,21,25]$. They developed a process model using a commercial CFD code FLUENT and explained the main physical phenomenon [25]. The works enabled them to formulate analytical models that were validated against experimental data [14]. The models predict the supply air temperature and velocity as follows:

$$
\begin{gathered}
T_{S}=-13.6+1.35 V_{i}+0.386 V_{o}+0.0958 \dot{m}_{a}-0.07 W F-0.022 D-0.0865 H \\
+0.686 T_{d b}+0.709 T_{w b} \\
V_{S}=0.107+0.706 V_{i}+0.21 V_{o}+0.00413 \dot{m}_{a}-0.00016 W F-0.024 H
\end{gathered}
$$

These analytical models are particularly important in that they account for the influences of water droplet sizes and air mass flow rates in conjunction with all other key variables such as air velocity, a water flow rate, a tower height, and the WBD. As the models include all key variables that significantly affect the performance, they can explicitly explain the down-draft evaporative cooling process.

\subsection{Two-way coupling of analytical models}

The EnergyPlus program employs a heat balance method and assumes well-mixed airflows within a thermal zone. The air heat balance algorithm in EnergyPlus assumes the supply air that a spray PDEC system discharges is well mixed with other natural airflows available in thermal zones at each time step. The energy balance formulation of the heat balance algorithm is as follows [29]: 


$$
\begin{gathered}
\sum_{i=1}^{N_{s l}} \dot{Q}_{l}+\sum_{i=1}^{N_{\text {Surf }}} h_{i} A_{i}\left(T_{s, i}-T_{z}\right)+\sum_{i=1}^{N_{\text {Zones }}} \dot{m}_{l} C_{p}\left(T_{z i}-T_{z}\right)+ \\
\dot{m}_{\text {inf }} C_{p}\left(T_{\infty}-T_{z}\right)=-\dot{m}_{\text {sys }} C_{p}\left(T_{\text {sup }}-T_{z}\right)
\end{gathered}
$$

Once the warmup convergence of the simulation at each time step is met, the air heat balance algorithm determines natural air flows in all thermal zones. The simulation manager calls the model that calculates the performance of a spray PDEC system. Within the new module that the authors implemented in the existing EnergyPlus program, the model calculates the mass flow rate $\left(m_{a}\right)$ over the wind catcher area $\left(A_{w c}\right)$ as follows:

$$
\dot{m}_{a}=\rho_{i} A_{w c} V_{o}
$$

As from the conservation of mass, the velocity of the inflows at the top of tower cross-section $\left(V_{t}\right)$ is expressed as:

$$
V_{t}=\frac{A_{w c}}{A_{t}} V_{o}
$$

The model calculates the supply air temperature and velocity at the outlet of a spray PDEC tower from equation 1 and 2 . The supply air mass flow rate $\left(\dot{m}_{S}\right)$ and velocity $\left(V_{S}\right)$ can then be determined from the conservation of mass as:

$$
\begin{gathered}
V_{s}=\frac{A_{t}}{A_{o}} V_{t} \\
\dot{m}_{s}=\rho_{s} A_{o} V_{s}
\end{gathered}
$$

The following material balance equation allows the calculation of evaporation rate $\left(Q_{w}\right)$ as follows:

$$
\begin{gathered}
\dot{m}_{a} \omega_{o}=\dot{m}_{a} \omega_{s}+\dot{m}_{w} \\
Q_{w}=\dot{m}_{s}\left(\omega_{s}-\omega_{o}\right) / \rho_{w}
\end{gathered}
$$

The sensible cooling rate $(q)$ that a spray PDEC system provides is expressed as:

$$
q=\dot{m}_{s} c_{p}\left(T_{z}-T_{s}\right)
$$

The supply mass flow rate of a spray PDEC system is then added to the mass flow rate of natural air flows in the fourth term in equation 3. The sensible cooling rate that forced air systems should provide with thermal zones is estimated from the energy balance equation by summing convective internal loads, convective heat transfer from zone surfaces, heat transfer from inter-zone air mixing and infiltration.

\section{Method}

Building energy simulation is being extensively used in evaluating the effects of numerous components in buildings such as building envelope, energy systems, and sustainable building technologies during decision-making processes for new buildings as well as existing buildings. A building simulation program allows solving the complex physical phenomena taking place in buildings and their surroundings. It has the ability to model buildings and their components under the design or actual conditions by processing inputs that characterize building components and the ambient environment. It can be said that building energy simulation is one of the best methods to examine the impact of a spray PDEC system on energy performance, indoor environment, and carbon footprint reduction. Among many building simulation programs, 
EnergyPlus was chosen in that the program has been extensively validated [30-34] and allows the predictions of building performance such as building thermal behaviors, indoor environments, building economics, and environmental impacts.

Short-term simulations were designed to analyze the cooling performance of a spray PDEC system on a typical summer day in two different climates. This is to verify the potential capability of a spray PDEC system in maintaining the comfortable indoor thermal environment, rather than looking at energy saving capability for a long-term period. A detailed simulation under an ideal condition also helps to take a close look at the influences of a spray PDEC system to thermal zones so that one can clearly perceive the benefits and the problems. To that end, this study focuses on one-day simulation under an ideal climatic condition for evaporative cooling in summer.

\subsection{Climatic condition}

Two cities in the US were selected: the city of Yuma, AZ, USA classified as a hot-dry climate (HD) and the city of Sacramento, CA, USA, classified as a warm-moderate climate (WM). The classification of the climate in this study was defined based on the variations in temperature and relative humidity on the selected days. An ideal summer day that is suitable for evaporative cooling was chosen from each climate. The WBD, relative humidity, and wind speed from TMY3 weather data during the summer season were the main factors for the selection.

Table 1 shows the variations of the dry-bulb temperature, the wet-bulb temperature, and the wind speed in the two climates. The maximum WBD and the average during the occupied hours were $24.14^{\circ} \mathrm{C}$ and $20.09^{\circ} \mathrm{C}$ in Yuma and $17.63^{\circ} \mathrm{C}$ and $12.22^{\circ} \mathrm{C}$ in Sacramento, respectively. In Yuma, the WBD was greater than $20^{\circ} \mathrm{C}$ for more than 9 hours of the day. The variations in wind speed during the unoccupied hours in both climates were very similar. The hot-dry climate shows more stable variation and the peak wind speed appears at $4.91 \mathrm{~m} / \mathrm{s}$. The wind speeds significantly increased over the afternoon hours in Sacramento with a peak of $5.2 \mathrm{~m} / \mathrm{s}$.

\subsection{Base case simulation}

The U.S. Department of Energy [35] developed a set of commercial reference building models for the purpose of energy efficiency research, based on the database from the Commercial Buildings Energy Consumption Survey (CBECS) that the energy information agency (EIA) publishes. They developed a set of 16 commercial building types in 16 different locations under three different construction vintages. Among those reference buildings, a new primary school reference building model in Phoenix, AZ, USA was chosen in that the primary school building model includes many thermal zones with different sizes and space types. No modifications were made to the original building model to represent climatic differences between the two climates in building energy systems and envelope.

A primary school building was selected in that it includes different space types and the physical size of each space type is different from each other. Students are frequently moving from one to another between classes, which cause substantial variations in the cooling loads. The indoor air quality in the school building is also very important since it affects the productivity of the occupants. A spray PDEC system is suitable to promptly respond to significant variations in the cooling loads and also to maintain the indoor air quality better by supplying a large volume of fresh air.

The one-story $6,871 \mathrm{~m}^{2}$ E-shaped reference school building consists of one main corridor with three wings. The space types in the building model are classrooms, an office, corridors, an auditorium, a gymnasium, a cafeteria, a kitchen, and a library. These space types are divided into 25 individual thermal zones as shown in Figure 1. The primary cooling system is a multi-zone single duct variable air volume (VAV) system with reheat for all classrooms, the office, the corridors, the auditorium, and the library. Packaged single zone air conditioning (PSZ-AC) units serve the subsidiary facilities such as the gymnasium, the kitchen, and the cafeteria. Indoor setpoint temperatures for all thermal zones were set at $24^{\circ} \mathrm{C}$ during the occupied hours from $6 \mathrm{AM}$ to $6 \mathrm{PM}$ and $27^{\circ} \mathrm{C}$ during the setback hours from $6 \mathrm{PM}$ to $6 \mathrm{AM}$. 
Table 1 Weather conditions of the representative day in two climates of interest.

\begin{tabular}{c|c|c|c|c|c|c}
\hline \multirow{2}{*}{ Time } & \multicolumn{3}{|c|}{ HD (Yuma) } & \multicolumn{3}{c}{ WD (Sacramento) } \\
\cline { 2 - 6 } & DBT $\left({ }^{\circ} \mathbf{C}\right)$ & WBT $\left({ }^{\circ} \mathbf{C}\right)$ & WS $(\mathbf{m} / \mathbf{s})$ & DBT $\left({ }^{\circ} \mathbf{C}\right)$ & WBT $\left({ }^{\circ} \mathbf{C}\right)$ & WS (m/s) \\
\hline 1 & 31.6 & 18.3 & 2.1 & 22.6 & 15.8 & 2.43 \\
2 & 30.0 & 17.0 & 0.88 & 22.4 & 15.6 & 1.69 \\
3 & 30.0 & 16.9 & 0 & 21.6 & 15.2 & 0.99 \\
4 & 29.4 & 17.0 & 0 & 20.9 & 14.8 & 0.29 \\
5 & 28.3 & 16.4 & 1.23 & 20.6 & 14.8 & 0.58 \\
6 & 27.8 & 15.1 & 2.68 & 20.6 & 15.1 & 1.64 \\
7 & 28.7 & 16.5 & 2.81 & 20.6 & 15.4 & 2.68 \\
8 & 30.4 & 16.6 & 1.96 & 22.5 & 16.6 & 3.10 \\
9 & 32.7 & 18.3 & 1.50 & 25.9 & 18.3 & 3.10 \\
10 & 35.5 & 18.6 & 2.14 & 29.2 & 19.8 & 3.10 \\
11 & 38.0 & 17.7 & 3.48 & 31.9 & 20.6 & 2.93 \\
12 & 39.9 & 18.1 & 3.23 & 34.1 & 21.2 & 2.57 \\
13 & 41.2 & 18.9 & 3.77 & 36.3 & 21.6 & 2.23 \\
14 & 42.3 & 19.5 & 3.73 & 37.7 & 21.9 & 2.68 \\
15 & 43.4 & 20.2 & 3.10 & 38.7 & 21.9 & 3.74 \\
16 & 43.9 & 20.5 & 3.39 & 39.6 & 22.0 & 4.78 \\
17 & 44.2 & 20.3 & 3.02 & 38.3 & 21.9 & 5.20 \\
18 & 44.4 & 20.3 & 2.60 & 35.3 & 21.0 & 5.20 \\
19 & 43.8 & 20.7 & 4.41 & 32.4 & 20.0 & 5.20 \\
20 & 41.0 & 21.2 & 4.91 & 29.7 & 19.2 & 4.91 \\
21 & 38.5 & 21.2 & 3.73 & 27.3 & 18.2 & 4.35 \\
22 & 36.8 & 20.7 & 2.81 & 24.9 & 17.1 & 3.81 \\
23 & 35.1 & 19.7 & 2.89 & 23.5 & 16.5 & 3.43 \\
24 & 34.1 & 19.2 & 2.52 & 22.7 & 16.1 & 3.07 \\
\hline
\end{tabular}

Among 25 thermal zones, this study analyzes the indoor environment in two representative spaces: a classroom and the office as all thermal zones showed a very similar tendency in the results. The large-scale space office and the small-scale space classroom have a volume of $1,764 \mathrm{~m}^{3}$ and $396 \mathrm{~m}^{3}$, respectively. The number of occupants and internal heat gains from internal heat sources differed from each space type. The detailed EnergyPlus simulation parameters and control strategies can be found in [36].

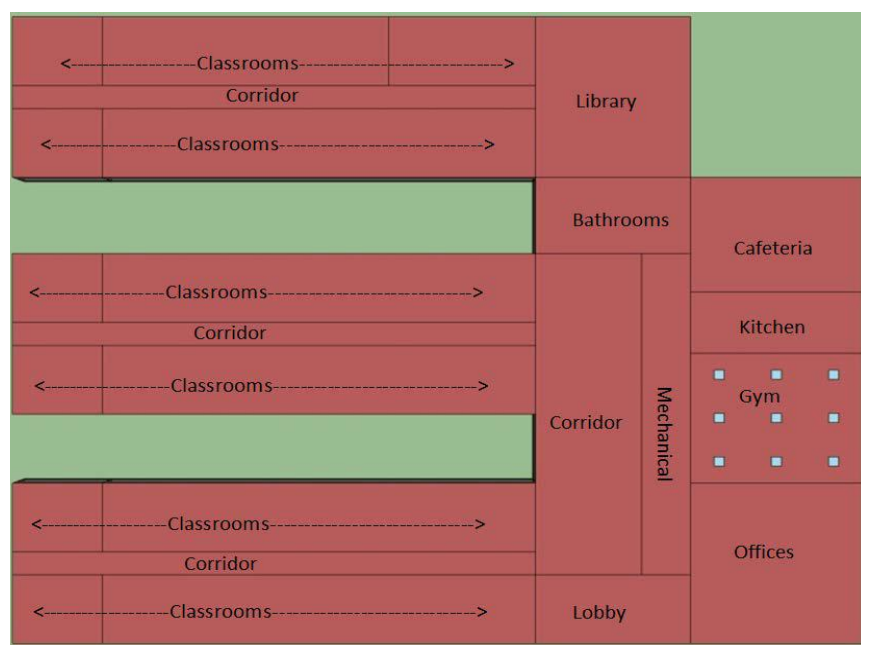

Adapted from [36]

Figure 1 Thermal zones for the simulations in the primary school building. 


\subsection{PDEC case simulation}

In one series of simulation, a spray PDEC system was modeled as they meet all space cooling loads in the thermal zones. That is, spray PDEC systems as a primary cooling system solely condition the entire school building with no additional cooling systems. These PDEC cases replaced the conventional cooling systems in the baseline model with spray PDEC systems. The simulations modeled that one spray PDEC system serves a single thermal zone. All the thermal zones remained unconditioned if the spray PDEC systems stopped the operation due to climatic conditions or during the unoccupied hours. No natural ventilation through the spray PDEC systems was assumed during the unoccupied hours, nor were mechanical ventilation set when the spray PDEC systems were turned off.

The simulations characterized typical features for the operation of a spray PDEC system. A spray PDEC system was typically designed to achieve the biggest temperature drop. The literature indicates that the operational conditions for a spray PDEC system are a constant water supply at a sufficient water flow rate, a high PDEC tower, a finer water drop, and a constant operation throughout the occupied hours [2,6,8-10, $20,26,27,37,38]$. To apply these typical characteristics of the spray PDEC system, it was sized to meet the peak cooling loads appearing during afternoon hours. All other features in the simulations remained the same as the baseline model.

This study runs preliminary simulations to size the spray PDEC systems. Depending on the physical size of the space types, they were categorized into three configurations. The following fields contributed to sizing the spray PDEC systems: tower height, wind catcher area, tower cross-sectional area, and water pump power consumption. The simulation inputs were determined based on the results of the preliminary simulations and the typical features found in the literature. In addition, losses of water and air were assumed to be 5\% in order to account for the uncertainty of the cooling efficiency. The total water consumption rate was thus the sum of supply water flow rate and 5\% of the supply. The supply air flow rate delivered to the spaces was 5\% less than the supply air flow rate at the outlet, which was determined by the analytical models. The operating schedule for the spray PDEC systems was set to be 6 AM through 8 PM. The simulations employed three different levels for the water flow rates as shown in Table 2.

The simulations applied a number of control strategies. Some building applications used simple on-off controls [6]. In addition to the typical operating features, the simulations applied potential on-off control for a spray PDEC system while the performance control of a spray PDEC system is atypical. The simulations assumed that the spray PDEC systems stayed off when the outdoor temperature was lower than $28^{\circ} \mathrm{C}$ and the outdoor relative humidity exceeded $40 \%$ in Yuma and 50\% in Sacramento. The field of minimum indoor temperature prevents overcooling in the morning due to a constant water flow rate. The simulations set the supply air temperature to be the value of the field when the calculated supply air temperature was lower than the minimum. The spray PDEC systems were assumed to be turned off when the supply air temperature was higher than the zone air temperature. This parameter prevents the supply of warmer air to the thermal zones. These control strategies were particularly included to avoid the overestimation of potential adverse impacts of the cool humid supply air to the indoor thermal environment, water consumption, and energy use. The other variables were set based on the results of the preliminary simulations as shown in Table 2.

The simulation uses a constant indoor air velocity due to the inherent limitation of the heat balance method. EnergyPlus includes a number of models to predict thermal comfort. Among those models, this study chose the Fanger's thermal comfort model as it accounts relevant variables and is being widely used. The Fanger's PMV index is determined from many environmental variables such as relative air velocity, air temperature, mean radiant temperature, and relative humidity and physiological variables such as activity, clothing, skin temperature, sweat rate, and thermal conductance [39]. The supply air flows discharged from a spray PDEC system affect all the environmental variables since the system delivers a large amount of cool humid air. The air velocity in a thermal zone should thus vary with time. The prediction of indoor air speed, in fact, involves such many factors as the locations of the supply and return outlets, occupants' activities, natural airflows, and inter-zonal airflows. The accurate prediction of the air velocity 
within the heat balance algorithm and the airflow network model is very complicated. To that end, the simulations use a constant indoor air velocity without attempting applying variable air velocity to a scripting schedule.

Table 2 Main input parameters for spray PDEC systems in the simulations.

\begin{tabular}{l|r|r}
\hline \multicolumn{1}{c|}{ Input Parameters } & Classroom & \multicolumn{1}{c}{ Office } \\
\hline Water flow rate $[1 / \mathrm{h}]$ & $100,150,200$ & $100,150,200$ \\
Effective tower height $[\mathrm{m}]$ & 5 & 10 \\
Water flow loss [\%] & 5 & 5 \\
Air flow loss [\%] & 5 & 5 \\
Rated pump power consumption $[\mathrm{W}]$ & $150,200,250$ & 9 \\
Area of wind catcher $\left[\mathrm{m}^{2}\right]$ & 6.25 & 25 \\
Tower cross-sectional area $\left[\mathrm{m}^{2}\right]$ & 16 & 30 \\
Diameter of water droplet $[\mu \mathrm{m}]$ & 30 & 23 \\
Minimum indoor temperature $\left[{ }^{\circ} \mathrm{C}\right]$ & 23 & $40(50)$ \\
Maximum outdoor RH $[\%]$ & $40(50)$ & 28 \\
Minimum outdoor temperature $\left[{ }^{\circ} \mathrm{C}\right]$ & 28 & \\
\hline
\end{tabular}

\section{Result}

\subsection{Cooling performance}

\subsubsection{Supply air conditions}

A significant difference in the supply air conditions over the three different water flow cases in both climates was observed as shown in Figure 3. The maximum differences appeared to be approximately $6.08^{\circ} \mathrm{C}$ at the last operating hour in Yuma and $5.09^{\circ} \mathrm{C}$ at $4 \mathrm{PM}$ in Sacramento. The supply air temperature in the classroom and the office dropped below the minimum of $23^{\circ} \mathrm{C}$ as soon as the spray PDEC systems operated. It was thus set to be the minimum. In Yuma, it began to rise as the WBD increased above approximately $21.83^{\circ} \mathrm{C}$ in the $1001 / \mathrm{h}$ water flow (WF) case and $23.22^{\circ} \mathrm{C}$ in the $1501 / \mathrm{h} \mathrm{WF}$ case while remained at the minimum temperature in the 2001/h WF case, except for the last operating hour. In Sacramento, the supply air temperature increased when the WBD rose above approximately $16.04^{\circ} \mathrm{C}$ in the $1001 / \mathrm{h} \mathrm{WF}$ case and $17.63^{\circ} \mathrm{C}$ in the $1501 / \mathrm{h} \mathrm{WF}$ case.

Another definite difference in the supply air temperature between the two climates was the operating hours. The spray PDEC systems operated from 7 AM to 7 PM in Yuma. The spray PDEC systems stopped at $7 \mathrm{PM}$ in all cases before the operating schedule ended in both climates. In Yuma, the supply air temperature in both $1001 / \mathrm{h}$ and $1501 / \mathrm{h} \mathrm{WF}$ cases began to increase at $6 \mathrm{PM}$ and rose by approximately $2.1^{\circ} \mathrm{C}$ in the classroom in $1001 / \mathrm{h} \mathrm{WF}$ case and $2.68^{\circ} \mathrm{C}$ in the office. It was $23.26^{\circ} \mathrm{C}$ in the $2001 / \mathrm{h} \mathrm{WF}$ case, which was still below the indoor setpoint temperature of $24^{\circ} \mathrm{C}$. In Sacramento, the operation of the spray PDEC systems delayed by $10 \mathrm{AM}$, due to the climatic conditions. The spray PDEC system also stopped the operation since the temperature of the outdoor air decreased in the 100 and 1501/h WF cases while the supply air temperature remained at the minimum for almost all the operating hours in the $2001 / \mathrm{h} \mathrm{WF}$ case.

Figure 2 illustrates that the relative humidity of the supply air remained below $80 \%$ in Yuma while above $80 \%$ in Sacramento in the two high WF cases. The relative humidity of the supply air stayed below or near $60 \%$ in the $100 \mathrm{WF}$ case throughout the operating hours in Yuma. It was the same in the morning in the other two WF cases and steadily increased up to $80.11 \%$ at the last operating hour in the office. In Sacramento, it rose to approximately $71.8 \%$ at the beginning of the operation and increased up to $90.6 \%$ at $4 \mathrm{PM}$, which showed the highest WBD of $17.63^{\circ} \mathrm{C}$. As the climatic conditions in Sacramento were relatively moderate and humid, a greater difference between the supply and the outdoor relative humidity in the 1001/h WF case was observed. The relative humidity of the supply air increased up to $69.36 \%$ at 7 PM in the classroom in Yuma and 69.77\% at 4 PM in both spaces in Sacramento. 
A small difference in the supply air conditions between the two representative spaces was found in the two lower WF cases. The 2001/h WF case resulted in a constant temperature variation in both climates as well as in both spaces. The variations in the supply air temperature and relative humidity between the classroom and the office were nearly identical in the 2001/h WF case. In the other two lower WF cases $1001 / \mathrm{h}$ and $1501 / \mathrm{h}$, a small difference in the supply air conditions were found between the classroom and the office. In Yuma, the difference in the supply temperature ranged from $0.08^{\circ} \mathrm{C}$ to $0.11^{\circ} \mathrm{C}$ in the $1501 / \mathrm{h}$ WF case and from $0.7^{\circ} \mathrm{C}$ to $0.98^{\circ} \mathrm{C}$ in the $1001 / \mathrm{h} \mathrm{WF}$ case, respectively. The maximum in relative humidity was $5.57 \%$ in the $1501 / \mathrm{h} \mathrm{WF}$ case and $4.14 \%$ in the $1001 / \mathrm{h} \mathrm{WF}$ case. The differences were relatively greater in Sacramento. The difference in temperature ranged from $0.87^{\circ} \mathrm{C}$ to $1.06^{\circ} \mathrm{C}$ in the $1501 / \mathrm{h} \mathrm{WF}$ case and from $0.12^{\circ} \mathrm{C}$ to $1.26^{\circ} \mathrm{C}$ in the other case, respectively. The maximum in relative humidity was $7.47 \%$ in the $1501 / \mathrm{h} \mathrm{WF}$ case and $7.85 \%$ in the $1001 / \mathrm{h} \mathrm{WF}$ case.

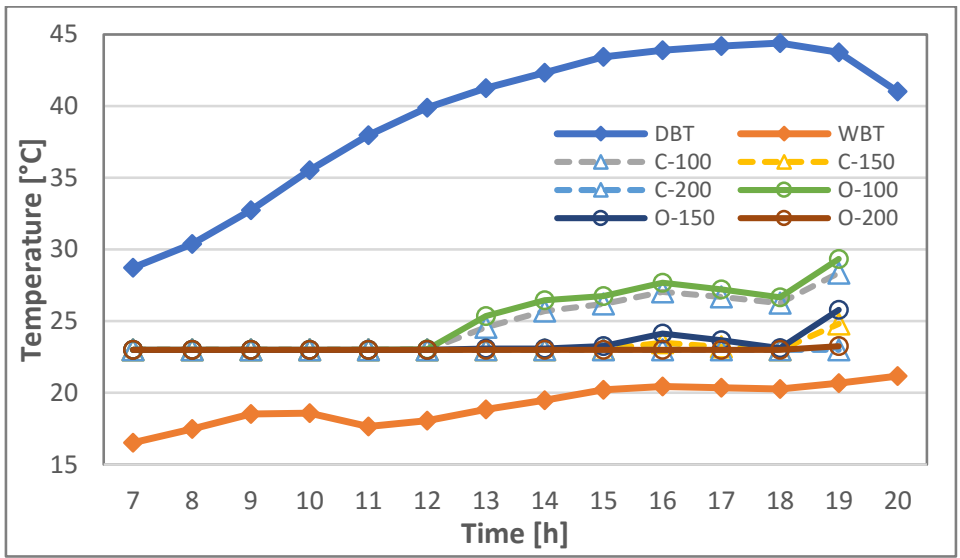

a) Temperature in Yuma

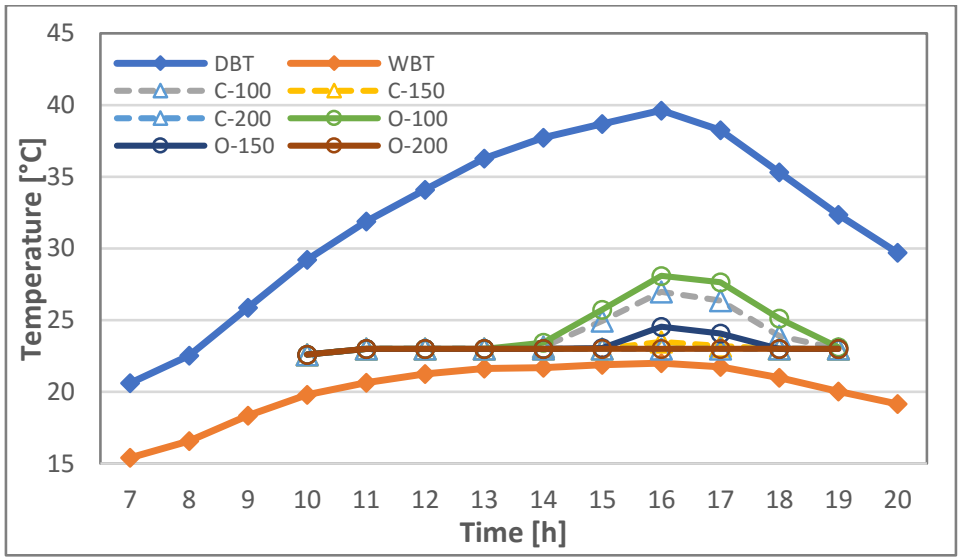

b) Temperature in Sacramento 


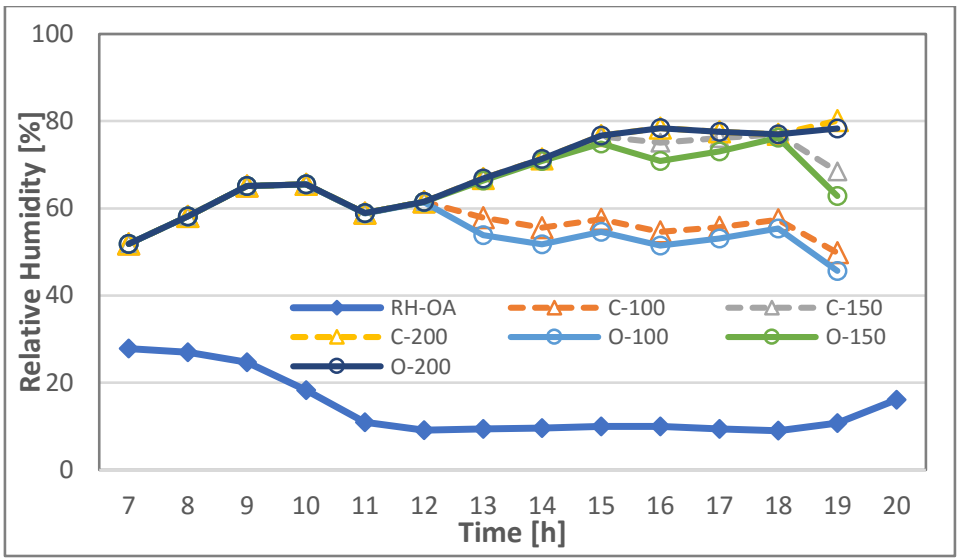

c) Relative humidity in Yuma

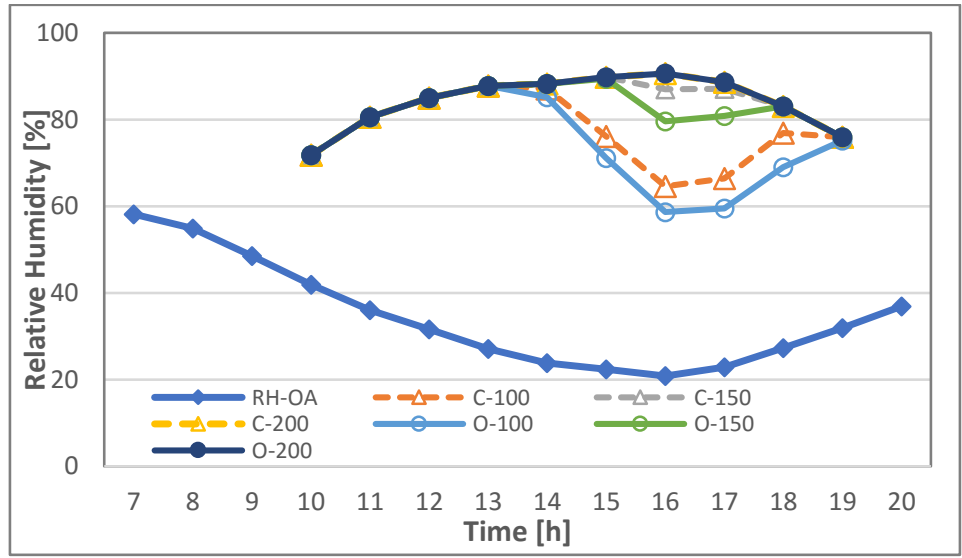

d) Relative humidity in Sacramento

Figure 2 Variations in the conditions of the supply air from the spray PDEC systems.

Table 3 and 4 show the hourly average volume flow rate of the supply air in both climates. As seen in equation 2, the wind speed of the air and the velocity of the inflows within the tower inside are key factors for the volume flow rate of the supply air. In both climates, the volume flow rate varied significantly along with the wind speed. One definite trend was that changes in the volume flow rate were greater at a lower wind speed since the momentum of the inflows weaker. Another trend shown in the results is that the volume flow rate decreased as the water flow rate increased. The reduction rate was very small and a little greater in the hot dry climate Yuma. Water evaporated more as the water flow rate increased and it likely lowered the momentum of the inflows. The increased water and air flow rates affect the reduction of the velocity of the supply air. As a result, the volume flow rate with the increment of a water flow rate decreased as high as $4.6 \%$ in Yuma and $2.8 \%$ in Sacramento. 
Table 3 Hourly supply air flow rate in the classroom $(\mathrm{C})$ and office $(\mathrm{O})$ in $\mathrm{m}^{3} / \mathrm{s}$ in Yuma.

\begin{tabular}{c|r|r|r|r|r|r|r}
\hline Time & WS $(\mathbf{m} / \mathbf{s})$ & \multicolumn{1}{c|}{ C-100 } & C-150 & C-200 & \multicolumn{1}{c|}{ O-100 } & \multicolumn{1}{c}{ O-150 } & \multicolumn{1}{c}{ O-200 } \\
\hline 7 & 2.81 & 8.38 & 8.29 & 8.19 & 11.82 & 11.70 & 11.57 \\
8 & 1.96 & 5.72 & 5.63 & 5.54 & 7.61 & 7.49 & 7.37 \\
9 & 1.50 & 4.29 & 4.19 & 4.10 & 5.34 & 5.22 & 5.10 \\
10 & 2.14 & 6.29 & 6.19 & 6.10 & 8.50 & 8.38 & 8.26 \\
11 & 3.48 & 10.44 & 10.35 & 10.26 & 15.07 & 14.95 & 14.83 \\
12 & 3.23 & 9.66 & 9.57 & 9.47 & 13.83 & 13.71 & 13.59 \\
13 & 3.77 & 11.34 & 11.25 & 11.16 & 16.49 & 16.37 & 16.25 \\
14 & 3.73 & 11.21 & 11.12 & 11.02 & 16.28 & 16.15 & 16.03 \\
15 & 3.10 & 9.26 & 9.17 & 9.07 & 13.19 & 13.07 & 12.95 \\
16 & 3.39 & 10.16 & 10.07 & 9.98 & 14.62 & 14.50 & 14.38 \\
17 & 3.02 & 9.00 & 8.90 & 8.81 & 12.78 & 12.65 & 12.53 \\
18 & 2.60 & 7.70 & 7.61 & 7.51 & 10.72 & 10.60 & 10.48 \\
19 & 4.41 & 13.33 & 13.24 & 13.14 & 19.62 & 19.50 & 19.38 \\
\hline
\end{tabular}

Table 4 Hourly supply air flow rate in the classroom (C) and office $(\mathrm{O}) \mathrm{in}^{3} / \mathrm{s}$ in Sacramento.

\begin{tabular}{c|r|r|r|r|r|r|r}
\hline Time & WS $(\mathbf{m} / \mathbf{s})$ & \multicolumn{1}{c|}{ C-100 } & \multicolumn{1}{c|}{ C-150 } & C-200 & \multicolumn{1}{c|}{ O-100 } & \multicolumn{1}{c}{ O-150 } & \multicolumn{1}{c}{ O-200 } \\
\hline 10 & 3.10 & 7.75 & 7.67 & 7.59 & 11.05 & 10.95 & 10.85 \\
11 & 2.93 & 8.74 & 8.65 & 8.56 & 12.39 & 12.27 & 12.14 \\
12 & 2.57 & 7.62 & 7.52 & 7.43 & 10.61 & 10.49 & 10.36 \\
13 & 2.23 & 6.55 & 6.45 & 6.36 & 8.91 & 8.79 & 8.67 \\
14 & 2.68 & 7.97 & 7.88 & 7.79 & 11.17 & 11.05 & 10.93 \\
15 & 3.74 & 11.27 & 11.18 & 11.09 & 16.38 & 16.26 & 16.14 \\
16 & 4.78 & 14.52 & 14.42 & 14.33 & 21.51 & 21.39 & 21.27 \\
17 & 5.20 & 15.82 & 15.73 & 15.63 & 23.57 & 23.45 & 23.33 \\
18 & 5.20 & 15.83 & 15.74 & 15.65 & 23.60 & 23.47 & 23.35 \\
19 & 5.20 & 15.84 & 15.75 & 15.66 & 23.62 & 23.50 & 23.38 \\
\hline
\end{tabular}

\subsubsection{Sensible cooling rate}

The simulations estimated the sensible cooling rate that the primary cooling system provided to meet the setpoint temperature in the spaces. The time series in the base case is sensible cooling rates that the mechanical cooling systems in the original reference building provided with the thermal zones. As the cooling systems met almost all space cooling loads, the sensible cooling rates in the base cases were almost identical with those in both the classroom and office. The maximum difference between the cooling loads and the cooling rates by the systems in the base case was only 7 watts. The sensible cooling rates in the base case can be said to be space cooling loads. As expected, the sensible cooling loads in Yuma were greater than Sacramento and the larger space office showed a greater difference between the two climates.

Figure 3 showed that the sensible cooling rates of the spray PDEC system varied with water flow rates significantly. One of the trends in the results of the simulations was that the sensible cooling rates in the three WF cases were fairly similar in the morning in both climates. As described in the previous subsection, the supply air temperatures were limited to the minimum indoor temperature of $23^{\circ} \mathrm{C}$ since the lowest water flow rate of 1001/h was enough to lower the supply air temperature in both climates. The $1001 / \mathrm{h} \mathrm{WF}$ case produced the highest sensible cooling rate in the morning as the mass flow rate was higher than the other two cases while the supply air temperature remained at the minimum. The differences across the three WF cases enlarged as the supply air temperature increased in the 1001/h WF case. The $2001 / \mathrm{h} \mathrm{WF}$ case generally showed the greatest cooling rate during afternoon hours in both spaces and climates as it resulted in the lowest supply air temperature. 
The spray PDEC systems met the space cooling loads for a longer time in the smaller space. The 1001/h WF case achieved the lowest sensible cooling rate during afternoon hours as the supply air temperature increased. The classroom showed a smaller difference in the cooling loads along with the increment of the water flow rates throughout the day due to a relatively lower space cooling load. The spray PDEC systems in the other 1501/h WF and 2001/h WF cases met the space cooling loads or removed more heats than the space cooling loads throughout the operating hours. The 1001/h WF case met the space cooling loads most of the operating hours except for 3 hours in the classroom in both climates while meeting them for 6 hours in the office in Yuma and 4 hours in the office in Sacramento. These results indicated that the spray PDEC systems can be effective to serve small-scale spaces that it has not traditionally served.

Significant variations in the sensible cooling rate with the water flow rates during afternoon hours appeared. In the morning, the sensible cooling rates across the water flow rates were fairly similar in all cases and the spray PDEC systems removed more heats than the space cooling loads. This trend seemed acceptable as it lessened the space cooling loads in the following hours and the space cooling loads increased. The sensible cooling rates in the $1001 / \mathrm{h}$ WF case were much less than the space cooling loads for 4 to 6 hours in Yuma and 2 to 3 hours in Sacramento. The other two WF cases in both space types and climates met the space cooling loads, except for a few hours. The spray PDEC systems removed almost twice the space cooling loads for the last 2 hours of the operation in Yuma when the space cooling loads dropped substantially for the last two operating hours. It could adversely affect the indoor thermal environment since the indoor temperature in the spaces decreased below the setpoint temperature. However, this trend may be beneficial to maintain the indoor thermal environment during the following unoccupied hours when the spaces remained unconditioned.

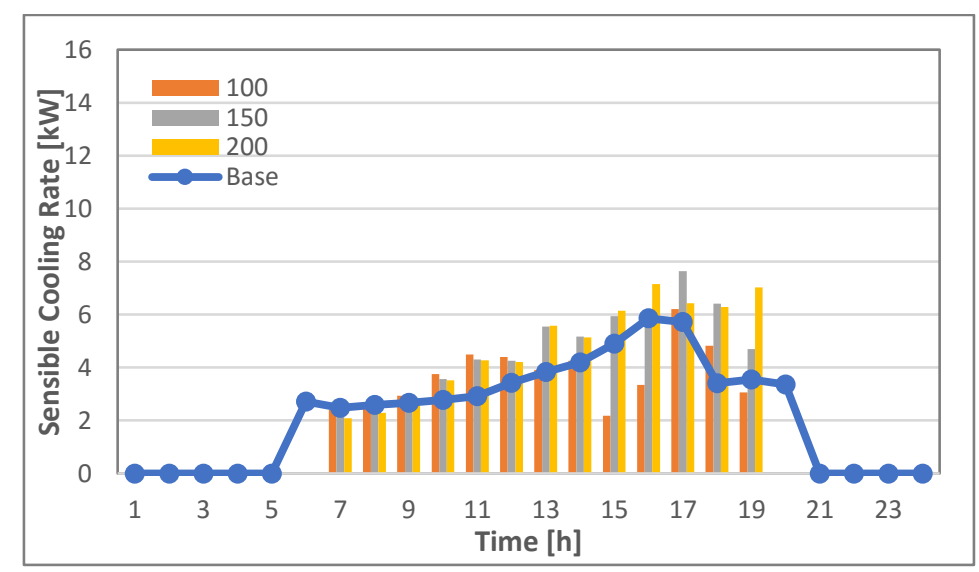

a) Classroom in Yuma

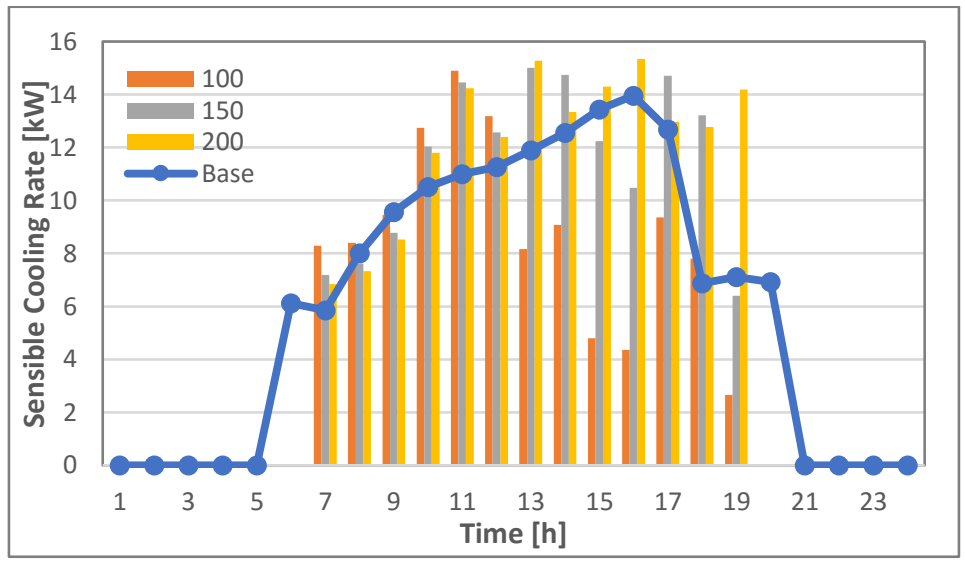

b) Office in Yuma 


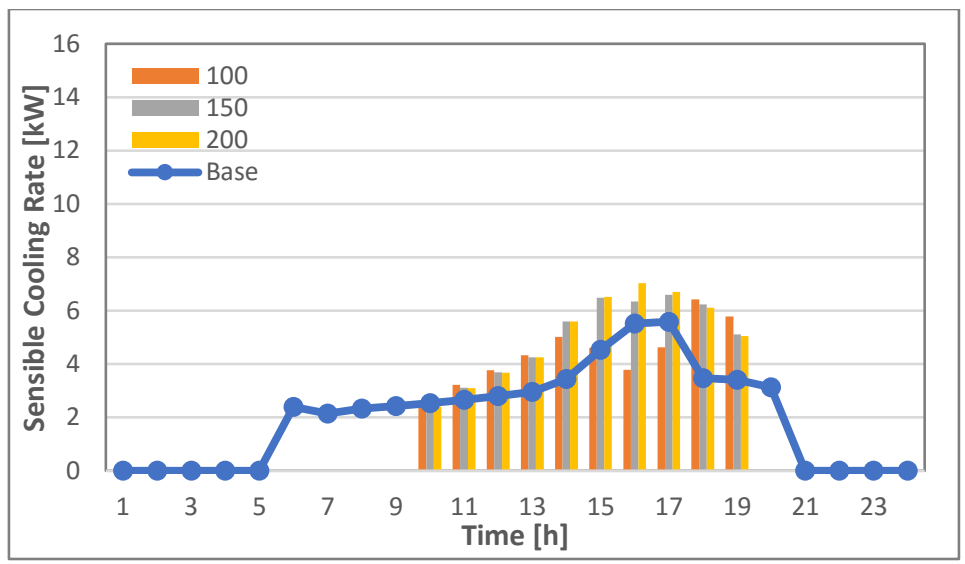

c) Classroom in Sacramento

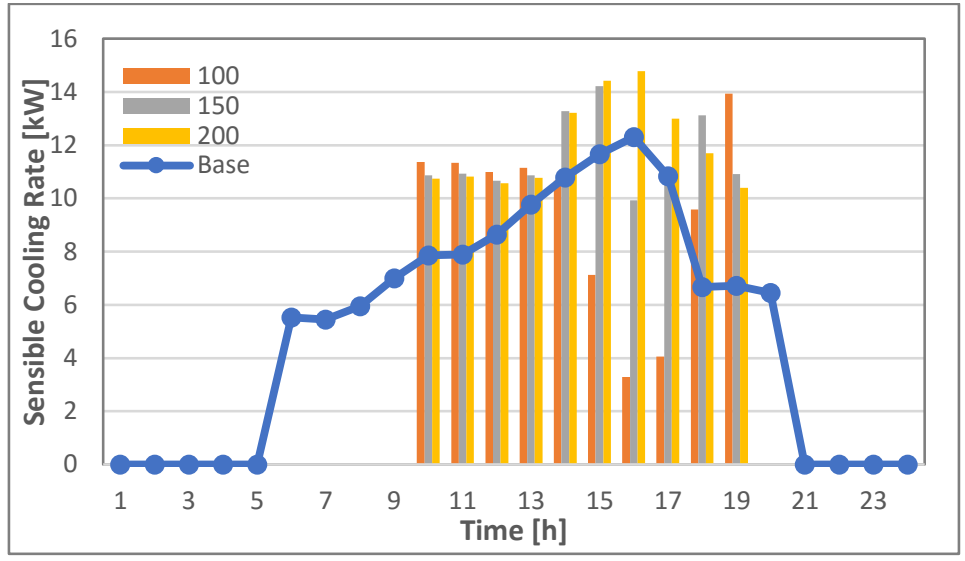

d) Office in Sacramento

Figure 3 Variations in sensible cooling rates in the two representative spaces

\subsubsection{Indoor thermal environment}

\section{Mean air temperature}

Figure 4 displayed the variations in the indoor mean air temperature in both spaces. The temperature variations in the 2001/h WF cases were the most consistent for the entire occupied hours in Yuma. The base cases showed a moderate downswing in the morning and an upswing later afternoon in both spaces. This trend is typical for in the spaces on the west side of buildings, due to the imbalance of solar radiation between the west and the east side as well as the heat storage effect of the building envelope. As the spray PDEC systems maintained a constant supply air temperature of $23^{\circ} \mathrm{C}$ in the morning, both spaces showed a marginal variation within a very narrow band in all PDEC cases in Yuma. The 1501/h WF case resulted in the increase of the supply air temperatures for a few afternoon hours in both spaces. The indoor temperature for afternoon hours in the $100 \mathrm{l} / \mathrm{h}$ WF case increased as the supply air temperature rose above the indoor temperature and the setpoint temperature. In Yuma, the maximum differences between the setpoint temperature of $24^{\circ} \mathrm{C}$ and the indoor air temperature were $3.42^{\circ} \mathrm{C}$ in the classroom and $4.06^{\circ} \mathrm{C}$ in the office, respectively. That is, the 1001/h WF case heated the spaces, supplying warmer airflows.

In Sacramento, a different trend was found in the morning. The base case showed a definite overcooling trend in the morning and the lowest temperature was $5.28^{\circ} \mathrm{C}$ below the setpoint temperature in the classroom. The downswing trend was stronger in the smaller space. It was mainly due to the imbalance of solar heat gains between the west side and the east side of the building. In the PDEC cases, both spaces remained unconditioned during the unoccupied hours and the operation of the spray PDEC systems delayed 4 hours 
due to the climatic conditions. The delay of the operation in the PDEC cases caused a $3.31{ }^{\circ} \mathrm{C}$ increase in the classroom and a $2.98^{\circ} \mathrm{C}$ increase in the office in the morning. However, the indoor air temperature variations were more stable than the base case once the spray PDEC systems operated. The 1001/h WF case also resulted in a hike for 4 afternoon hours in both spaces when the WBD was greater than approximately $14.3^{\circ} \mathrm{C}$. The temperature hike in the $1501 / \mathrm{h}$ WF case appeared for only 2 hours when the WBD was approximately $16.5^{\circ} \mathrm{C}$ and above.

The PDEC cases in both climates maintained a lower indoor air temperature than the setpoint in the morning. The indoor temperatures in the classroom during morning hours were $0.3^{\circ} \mathrm{C}$ to $0.78^{\circ} \mathrm{C}$ lower than the setpoint in Yuma and $0.41^{\circ} \mathrm{C}$ to $0.68^{\circ} \mathrm{C}$ lower in Sacramento. The same trend in the indoor temperature variations was found in the office while the temperature differences were smaller due to greater space cooling loads. The spray PDEC systems maintained a constant supply temperature of $23^{\circ} \mathrm{C}$ as the minimum indoor temperature control was applied to the operation in the morning. The $2001 / \mathrm{h} \mathrm{WF}$ case retained a very consistent temperature variation within a very narrow band throughout the day and it maintained a better temperature variation than the base case.

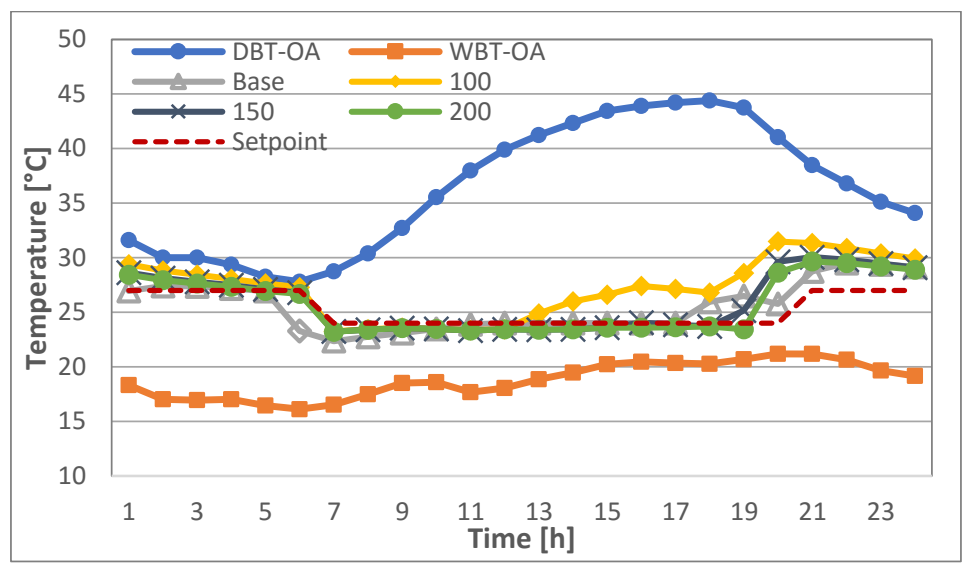

a) Classroom in Yuma



b) Office in Yuma 


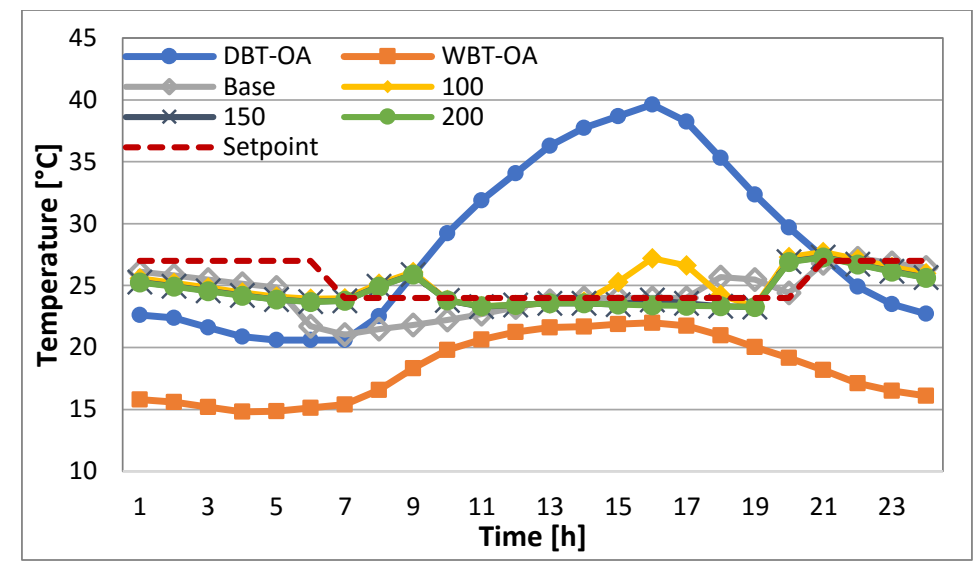

c) Classroom in Sacramento



d) Office in Sacramento

Figure 4 Variations in the indoor mean air temperature

\section{Relative humidity}

Figure 5 depicts the variations in the indoor relative humidity. In Yuma, the indoor relative humidity increased as the temperature control mode returned to an occupied mode and as the primary cooling systems humidified the supply air in the base case. In the PDEC cases, the indoor relative humidity in both spaces increased up to $40.21 \%$ in the classroom $40.1 \%$ in the office within the first 3 hours of the operation of the spray PDEC systems. The $2001 / \mathrm{h}$ WF case increased the indoor relative humidity up to $22.78 \%$ in the classroom and $21.88 \%$ in the office during afternoon hours while the $1001 / \mathrm{h} \mathrm{WF}$ case led $15.45 \%$ increase in the classroom and $14.53 \%$ increase in the office. The variations in the $1501 / \mathrm{h} \mathrm{WF}$ case were very similar to the WF 2001/h case and these two WF cases maintained an increase of the indoor relative humidity around $30 \%$ for more than half of the day. The daily variations in the $1501 / \mathrm{h}$ and $2001 / \mathrm{h} \mathrm{WF}$ cases were very similar to those in the base case. As the supply air temperature was limited to the minimum indoor temperature of $23^{\circ} \mathrm{C}$ in the morning, the difference between the indoor and outdoor relative humidity was below $18 \%$. The variations in the PDEC cases were also fairly constant during the unoccupied hours.

A greater variability was found in Sacramento. The outdoor relative humidity varied with time and formed a V-shape variation in the two lower WF cases for some occupied hours. The daily difference in the outdoor relative humidity was $27.34 \%$ and the maximum relative humidity was $58.17 \%$ at $7 \mathrm{AM}$. The humid supply air increased the humidity level of the indoor air by $13.1 \%$ in the classroom and $16.8 \%$ in the office within 2 hours of the operation of the spray PDEC systems. The peak in the indoor relative humidity was approximately $60 \%$ in the classroom in the morning while that in the base case was approximately 
$50.57 \%$ at $11 \mathrm{AM}$ in the classroom. The indoor relative humidity varied within $7.63 \%$ band in the classroom and $6.13 \%$ band in the office. The maximum difference between the outdoor and indoor relative humidity in the $2001 / \mathrm{h}$ WF case reached up to $31.54 \%$. The variations in the PDEC cases were approximately 5.6\% higher in the classroom and $8.7 \%$ higher in the office than those in the base case during the occupied hours. Overall, the indoor relative humidity stayed below the recommended value of $60 \%$ throughout the day.

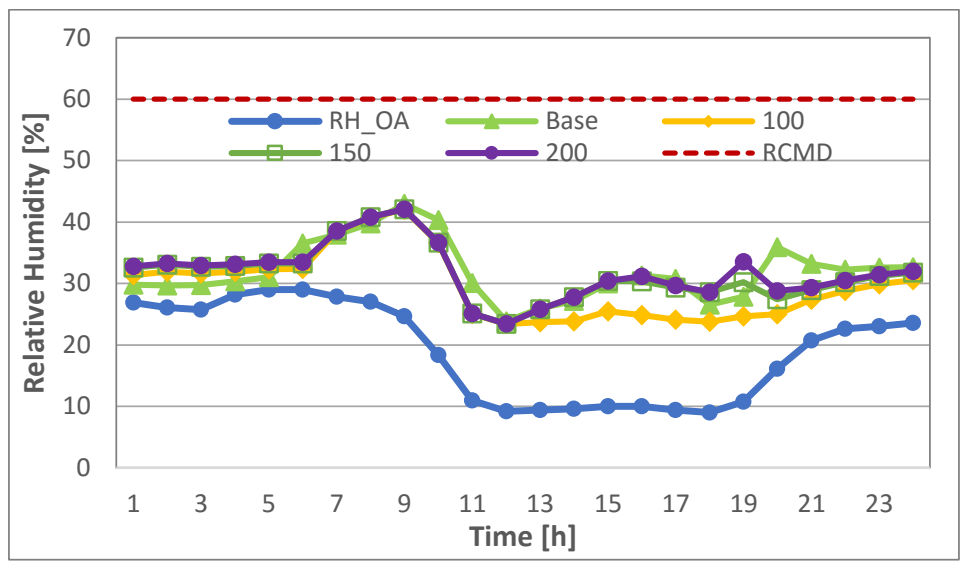

a) Yuma

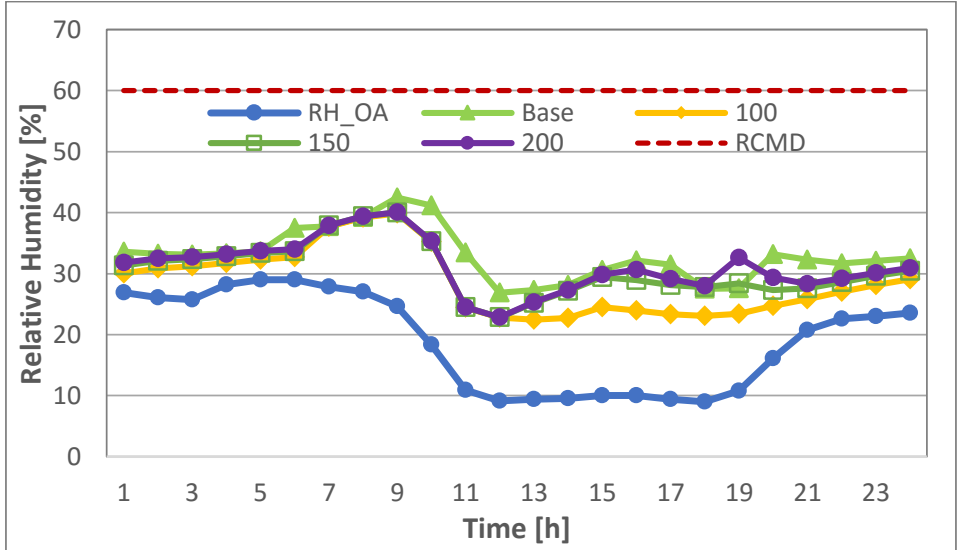

b) Sacramento

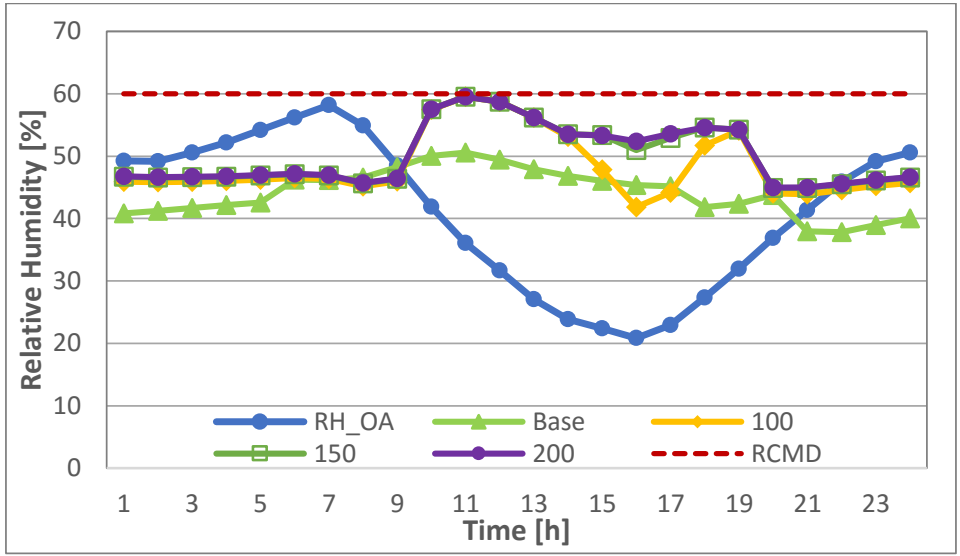

c) Classroom in Sacramento 


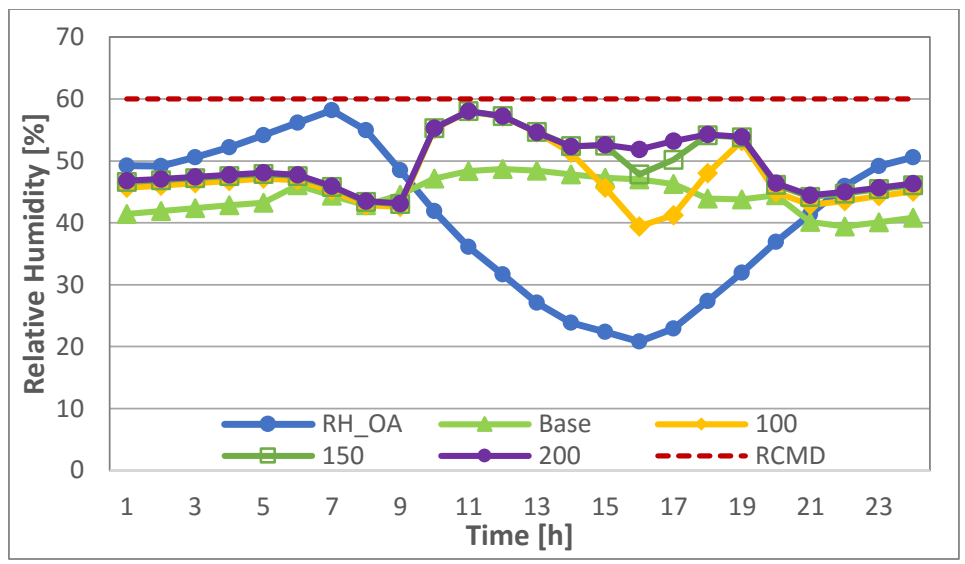

d) Office in Sacramento

Figure 5 Variations in the indoor relative humidity.

\section{Thermal comfort}

The simulations predicted Fanger's PMV index as shown in Figure 6. The PMV values between +0.5 and -0.5 are generally considered that occupants in a space feel thermally comfortable. The PMV values throughout the occupied hours in the two higher WF cases were more stable than those in the base case in Yuma. As described above, these two cases well maintained the indoor air temperature and relative humidity during the occupied hours. The PMV values sharply increased in the classroom after the spray PDEC systems stopped the operation mainly due to the heat storage effect of the building envelope. The same trend was found in the office. However, the magnitude was relatively moderate as the office was located at the south-east corner of the building, which results in a lower heat storage effect. The 1001/h WF case showed a much greater variability as the spray PDEC systems failed to meet the space cooling loads for afternoon hours.

In Sacramento, the PMV values were closer to the neutral line during the operating hours of the spray PDEC systems. In the base case, the PMV values dropped in the morning to approximately -1.1 in the classroom and to -0.59 in the office, due to the overcooling trend. The opposite trend in the PDEC cases in the PDEC cases appeared as both spaces remained unconditioned until the spray PDEC systems began to operate. The 1001/h WF case caused hikes for some afternoon hours. Other than those hours, the case maintained the PMV values below the recommended upper limit. The other two WF cases lowered the PMV values to the neutral in both spaces as the spray PDEC system started. The PMV values floated near the neutral line within a very narrow band throughout the occupied hours. The PMV variations in the PDEC cases during the unoccupied hours were steadier than the base case. 


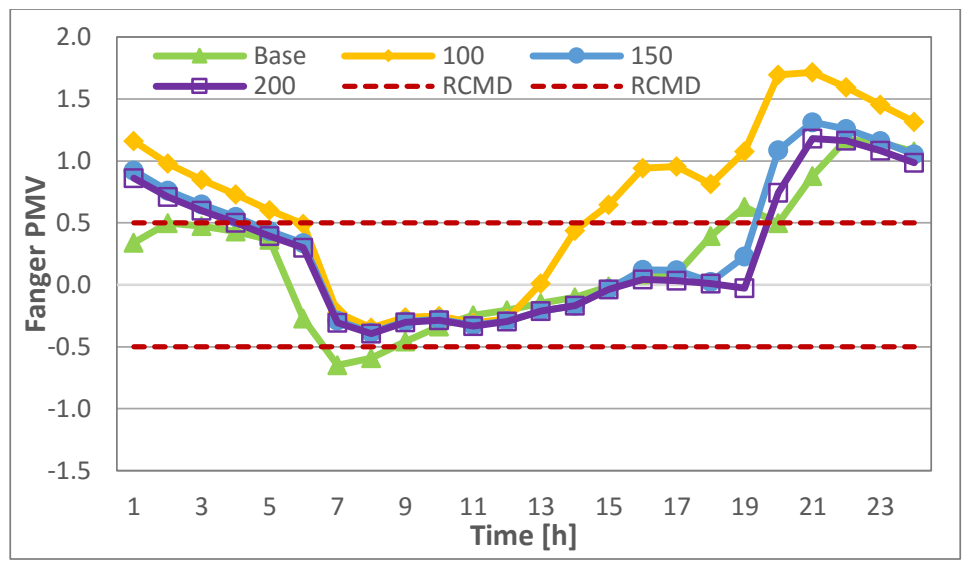

a) Classroom in Yuma



b) Office in Yuma

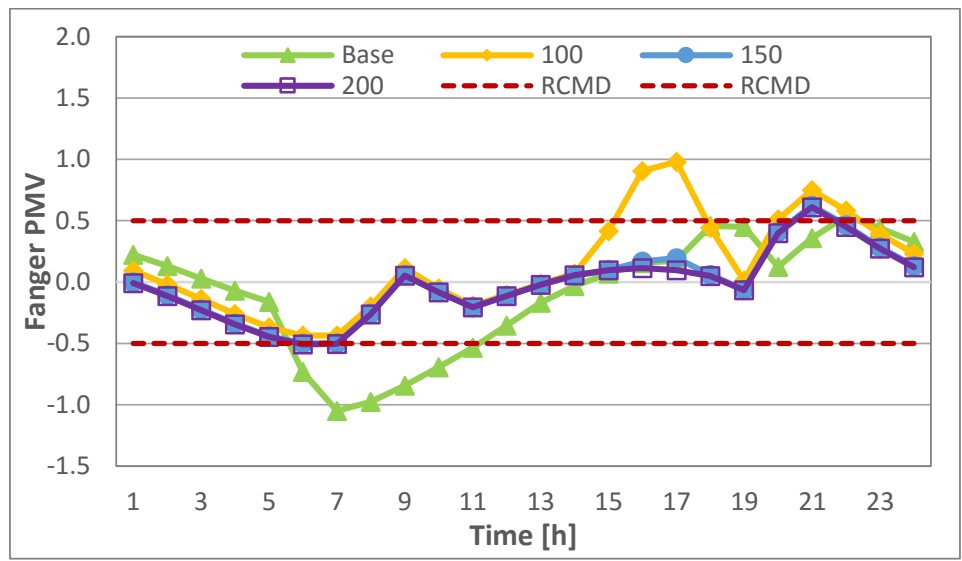

c) Classroom in Sacramento 


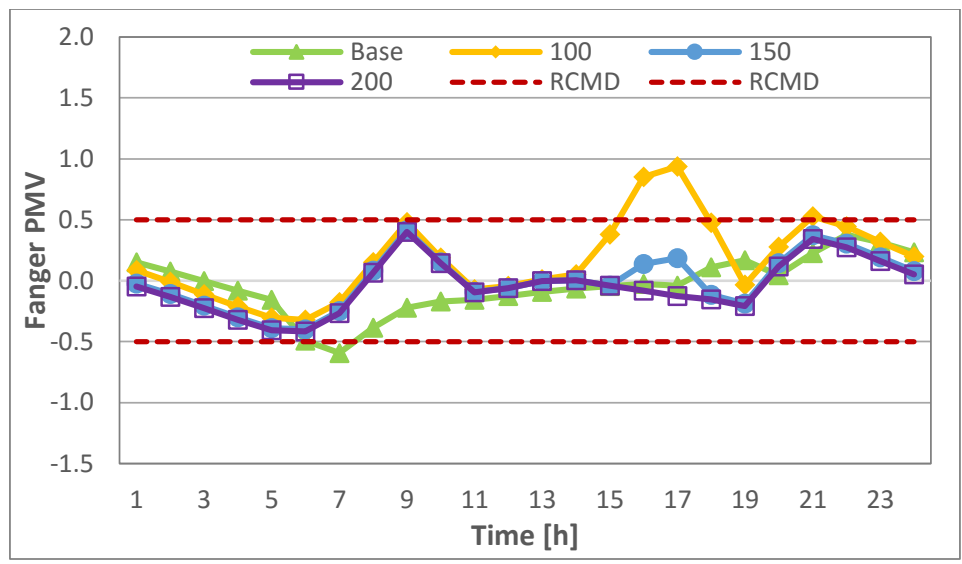

d) Office in Sacramento

Figure 6 Variations in Fanger's PMV index.

\subsection{Energy performance}

Table 5 summarizes the electricity consumptions for the cooling systems and facilities, the water consumption, and the carbon dioxide production by the building facilities. The energy consumption in the PDEC cases is solely dependent on the operation of the water pump. The rated pump power consumption was set to be $150 \mathrm{~W}, 200 \mathrm{~W}$, and $250 \mathrm{~W}$ along the water flow rate of $1001 / \mathrm{h}, 1501 / \mathrm{h}$, and $2001 / \mathrm{h}$, respectively. The electricity for cooling and carbon production slightly increased with the increments of the water flow. The percentage reduction rate in the cooling energy against the base case reached to $96.8 \%$ in Yuma and $96.2 \%$ in Sacramento. The fan energy consumptions were approximately $8.5 \%$ of the total in Yuma and $11.8 \%$ of the total in Sacramento. The energy consumed by the fan was also saved as the spray PDEC systems formed natural airflows.

It is noted that the total percentage reduction may vary in the operation of the spray PDEC systems in real buildings. For instance, the operation may require the aid of fans to form well-mixed air flows in a space or to depressurize part of the space near the outlet of the spray PDEC system to maintain the natural air flows. While the percentage reduction may be lower than the predicted in this study, it is apparent that a spray PDEC system will result in a sizable energy saving as it needs only one component that uses electricity. A number of studies reported energy savings of up to $83 \%[2,8,12,40]$.

The water consumption increased significantly in the PDEC cases as the downdraft evaporative cooling process needed a large amount of water to lower the temperature of the inflows. The spray PDEC systems in the $2001 / \mathrm{h} \mathrm{WF}$ case in Yuma required as large as $152.4 \mathrm{~m}^{3}$ of water in order to treat the hot dry outdoor air. The total energy saving in the PDEC cases should thus account for the increase of water consumption. The simulations estimated that the spray PDEC systems reduced the carbon production by $56.7 \%$ in Yuma and by $47.1 \%$ in Sacramento.

The PDEC cases in Sacramento also achieved substantial energy savings. The degree of energy saving in Sacramento was similar to that in Yuma, requiring much less water. The water consumption in Sacramento was relatively lower as the climatic conditions delayed the operation of the spray PDEC systems in the morning. This result suggested that a spray PDEC system may be viable in a wider range of the climates than the hot dry climate which is known as the most suitable climate for evaporative cooling. 
Table 5 Comparisons of energy performance in the school building in both climates.

\begin{tabular}{|c|c|c|c|c|}
\hline \multicolumn{5}{|c|}{ Yuma } \\
\hline Meters & Base & WF 100 & WF 150 & WF 200 \\
\hline Cooling:Electricity [MJ] & 7072.5 & 229.3 & 247.8 & 266.8 \\
\hline Electricity:Facility [MJ] & 13410.8 & 5745.5 & 5763.4 & 5783.0 \\
\hline Fans:Electricity [MJ] & 601.7 & 0 & 0 & 0 \\
\hline Cooling:MainsWater $\left[\mathrm{m}^{3}\right]$ & 1.5 & 109 & 135.1 & 152.4 \\
\hline Carbon Equivalent [kg] & 1141.1 & 494.2 & 495.7 & 497.3 \\
\hline \multicolumn{5}{|c|}{ Sacramento } \\
\hline Meters & Base & WF 100 & WF 150 & WF 200 \\
\hline Cooling:Electricity [MJ] & 4554.5 & 173.5 & 187.2 & 201.8 \\
\hline Facility:Electricity [MJ] & 10808 & 5674.2 & 5688.6 & 5702.5 \\
\hline Fans:Electricity [MJ] & 538.9 & 0 & 0 & 0 \\
\hline HVAC:MainsWater $\left[\mathrm{m}^{3}\right]$ & 1.5 & 81.3 & 100.6 & 113.4 \\
\hline Carbon Equivalent $[\mathrm{kg}]$ & 923.1 & 488.2 & 488.9 & 490.6 \\
\hline
\end{tabular}

\section{Conclusion}

While studies investigated how much energy can be saved by integrating a spray PDEC system, the capability of a spray PDEC system for space cooling has not been well studied to data. To comprehensively analyze the performance of a spray PDEC system, this study coupled a new module for a spray PDEC system with the existing heat balance algorithm in EnergyPlus and examined the system response of a spray PDEC system by using the US DOE's Primary School Reference Building model. The development of the simulation module is currently the only method that can accurately analyze the various impacts of a spray PDEC system. It enables the prediction of the variations in the cooling loads along with the change of water flow rate in spaces where a spray PDEC system serves. The prediction has never been possible.

It simulated a base case using the reference building model and three PDEC cases with a modified reference building model in two different climates. It applied the typical operating conditions for a spray PDEC system with on-off controls. An ideal summer day was chosen in a hot-dry climate and a warmmoderate climate. It predicted energy consumptions, indoor thermal environment, and system performances. The main findings of the study are as follows.

- The control of the minimum temperature contributes to lessening overcooling trend and maintain the sensible cooling rates.

- The spray PDEC system may increase the space cooling loads when the water flow rate is not enough to lower the supply air temperature below the setpoint temperature.

- An overcooling by a spray PDEC system in some degrees in the morning would be acceptable when the space cooling loads increase.

- The indoor relative humidity variations in both climates can be maintained below the recommended value.

- The PMV variations in the 150 and 200 WF cases were better than the base cases in both climates.

- The spray PDEC systems required less than $10 \%$ of the electricity for cooling in the base cases while the reduction rate vary with various factors related to building operations.

- The water flow rate greater than $1501 / \mathrm{h}$ is recommended to meet the variable space cooling loads under the given conditions in the two climates.

- The spray PDEC system can be better in serving a small-scale space that a spray PDEC system has not typically served.

- A spray PDEC system may be used in a wider range of climatic conditions than a hot-dry climate. 
The results of the simulations showed that a spray PDEC system could be a primary cooling system under the climatic conditions considered in this study. The thermal environment in the 150 and $200 \mathrm{WF}$ cases was better than the base case. However, the system response of a spray PDEC system to the variations in the cooling loads was not as sensitive as the conventional air-conditioning systems. To that end, finer control of the cooling performance of a spray PDEC system is needed to maximize the energy efficiency of the system, especially when the space cooling loads decrease. In addition, the control of the mass flow rate of the inflows should be considered as it is found to be a key factor for the capacity of a spray PDEC system.

\section{Reference}

[1] Bahadori, M.N. (1985) An improved design of wind towers for natural ventilation and passive cooling. Solar Energy, 35, 2, 119-129.

[2] Givoni, B. (1994) Passive and low energy cooling of buildings. Van Nostrand Reinhold, New York, USA.

[3] Mazidi, Mohsen, Dehghani, Alireza, and Aghanajafi, Cyrus. (2006) Wind towers' role in natural air conditioning and passive cooling of buildings in hot arid regions. Wseas Transactions of Fluid Mechanics, 11, 1, 959-966.

[4] Yaghoubi, M.A., Sabzevari, A., and Golneshan, A.A. (1991) Wind towers: measurement and performance. Solar Energy 47, 2, 97-106.

[5] Bahadoria, M.N., Mazidib, M. and Dehghanic, A.R. (2008) Experimental investigation of new designs of wind towers. Renewable Energy, 33, 2273-2281.

[6] Ford, B., Francis, E. and Shiano-Phan, R. (2010) The architecture and engineering of downdraught cooling. PHDC Press.

[7] Torcellini, P., Long, N., Pless, S. and Judkoff, R. (2005) Evaluation of the low-energy design and energy performance of the Zion National Park Visitors Center. Technical Report, NREL/TP-550-34607.

[8] Cunningham, W. and Thompson, T. (1986) Passive cooling with natural draft cooling towers in combination with solar chimneys. Passive and Low Energy Architecture, Hungary, 1-5.

[9] Chiesa, Giacomo, Grosso, Mario, Bogni, Alessio, and Garavaglia, Giacomo. (2016) Passive downdraught evaporative cooling system integration in existing residential building typologies: a case study. $8^{\text {th }}$ International Conference on Sustainability in Energy and Buildings, Turin, Italy

[10] Pearlmutter, D., Erell, E., Etzion, Y., Meir, I.A. and Di, H. (1996) Refining the use of evaporation in an experimental down-draft cool tower. Energy and Buildings, 23, 3, 191-197.

[11] Schiano-Phan, Rosa and Ford, Brian. (2008) Post occupancy evaluation of non-domestic buildings using downdraught cooling: case studies in the US. Passive and Low Energy Architecture, Dublin.

[12] Thompson, T.L., Chalfoun, N.V., and Yoklic, M.R. (1994) Estimating the performance of natural draft evaporative coolers. Energy Conservation and Management, 35, 11, 909-915.

[13] Erell, Evyatar, Pearlmutter, David, and Etzion, Yair (2008) A multi-stage down-draft evaporative cool tower for semi-enclosed spaces: Aerodynamic performance. Solar Energy 82, 5, 420-429.

[14] Kang, Daeho and Strand, Richard K. (2016) Significance of parameters affecting the performance of a passive down-draft evaporative cooling (PDEC) tower with a spray system. Applied Energy, 178, 269280.

[15] Elgendy, E., Mostafa, A., and Fatouh, M. (2015) Performance enhancement of a desiccant evaporative cooling system using direct/indirect evaporative cooler. International Journal of Refrigeration, 51, 77-87. 
[16] Heidarinejad, Ghassem, Bozorgmehr, Mojtaba, Delfani, Shahram, and Esmaeelian, Jafar. (2009) Experimental investigation of two-stage indirect/direct evaporative cooling system in various climatic conditions. Building and Environment, 44, 2073-2079.

[17] Salmerón, J.M., Álvarez, S., Sánchez, J, Ford, B., and Gillott, M. (2012) Analysis of a PHDC (Passive and Hybrid Downdraft Cooling) Experimental Facility in Seville and its Applicability to the Madrid Climate. Journal of Ventilation, 10, 4, 391-404.

[18] Soutullo, S., Sanjuan, C. and Heras, M.R. (2012) Energy performance evaluation of an evaporative wind tower. Solar Energy, 86, 1396-1410.

[19] Kang, Daeho and Strand, Richard K. (2015) Implementation of analytical models for passive downdraft evaporative cooling (PDEC) tower with spray systems. 14th Conference of IBPSA, Hyderabad, India.

[20] Givoni, B. (1991) Performance and applicability of passive and low-energy cooling systems." Energy and Buildings, 17: 177-199.

[21] Kang, Daeho and Strand, Richard K. (2009) Simulation of passive down-draught evaporative cooling (PDEC) systems in EnergyPlus. Building Simulation 2009, Glasgow, Scotland.

[22] Thomas, Leena and Baird, George. (2006) Post-occupancy evaluation of passive downdraft evaporative cooling and air-conditioned buildings at Torrent Center, Ahmedabad, India. 40th Annual Conference of the Architectural Science Association ANZAScA, 97-104.

[23] Bajwa, Maqsood, Aksugur, Erdal, and Al-Otaibi, Ghazi. (1993) The potential of the evaporative cooling techniques in the Gulf region of the Kingdom of Saudi Arabia. Renewable Energy, 3, 1, 15-29.

[24] Hughes, B.R., Calautit, J.K., and Ghani, S.A. (2012) The development of commercial wind towers for natural ventilation: A review. Applied Energy 92, 606-627.

[25] Kang, Daeho and Strand, Richard K. (2013) Modeling of simultaneous heat and mass transfer within passive down-draft evaporative cooling (PDEC) towers with spray in FLUENT. Energy and Buildings, 62, 196-209.

[26] Robinson, D., Lomas, K.J., Cook, M.J. and Eppel, H. (2004) Passive down-draught evaporative cooling: Thermal modeling of an office building. Indoor + Built Environment, 13, 205-221.

[27] Ford, Brian. (1998) Cooling without air conditioning. Renewable Energy 15, 177-182.

[28] Omar Dhia Sadulah Al-Hassawi. (2017) Advancing Performance of Passive Downdraft Cooling Towers, Diss.

[29] U.S. Department of Energy. (2016) EnergyPlus Engineering Reference: The Encyclopedic Reference.

[30] Henninger, R.H. and Witte, M.J. (2015) EnergyPlus Testing with ASHRAE 1052-RP Toolkit Building Fabric Analytical Tests, Technical Report, US Department of Energy

[31] Henninger, R.H. and Witte, M.J. (2015) EnergyPlus Testing with HVAC Equipment Component Tests, Technical Report, US Department of Energy

[32] Henninger, R.H. and Witte, M.J. (2015) EnergyPlus Testing with IEA BESTEST In-Depth Ground Coupled Heat Transfer Tests Related to Slab-on-Grade Construction, Technical Report, US Department of Energy

[33] ANSI/ASHRAE Standard 140-2011. Standard Method of Test for the Evaluation of Building Energy Analysis Computer Programs.

[34] U.S. Department of Energy. (2018) Testing and Validation. January, 2018. energyplus.net/testing, 
[35] Torcellini, P. et. al. (2011) U.S. Department of energy commercial reference building models of the national building stock. Technical Report, NREL/TP-5500-46861.

[36] Fernandez, N., Katipamula, S., Wang, W, Xie, Y., Zhao, M., and Corbin, C. (2017) Impacts of commercial building controls on energy savings and peak load reduction. Technical Report, PNNL25985.

[37] Bowman, N.T., Eppel, H., Lomas, K.J., Robinson, D. and Cook, M.J. (2000) Passive downdraught evaporative cooling I. concept and precedents. Indoor + built environment, 9, 284-290.

[38] Givoni, B. (1994) Passive and Low Energy Cooling of Buildings. Van Nostrand Reinhold, New York, USA.

[39] P. O. Fanger. (1970) Thermal Comfort. McGraw-Hill, New York.

[40] Melo, C. and Guedes, Manuel Correia. (2006) Passive downdraught evaporative cooling applied on existing fabric: using traditional chimney and new dwelling as case study in Portugal. In proceeding of the PLEA, Geneva, Switzerland.




$W S \quad$ wind speed in $\mathrm{m} / \mathrm{s}$

$\rho_{i} \quad$ density of inflows in $\mathrm{kg} / \mathrm{m}^{3}$

$\rho_{s} \quad$ density of supply air in $\mathrm{kg} / \mathrm{m}^{3}$

$\rho_{w} \quad$ density of water in $\mathrm{kg} / \mathrm{m}^{3}$

$\omega_{o} \quad$ humidity ratio of inflows in $\mathrm{kg}_{\mathrm{w}} / \mathrm{kg}_{\mathrm{a}}$

$\omega_{s} \quad$ humidity ratio of supply air in $\mathrm{kg}_{\mathrm{w}} / \mathrm{kg}_{\mathrm{a}}$ 